\title{
Phenytoin Measurement
}

National Cancer Institute

\section{Source}

National Cancer Institute. Phenytoin Measurement. NCI Thesaurus. Code C147413.

The determination of the amount of phenytoin present in a sample. 